\title{
RADIOACTIVE WASTE DISPOSAL SOLUTIONS: A GEOLOGICAL PERSPECTIVE
}

by

W.S. Fyfe

\begin{abstract}
Reasonable solutions to the problem of radioactive waste disposal exist now and it may be that in the future nuclear power will prove environmentally more desirable than coal power. This review concentrates on some of the major questions faced by geoscientists around the world as they develop better and more economic concepts to deal with the problem of effective and safe nuclear waste disposal.
\end{abstract}

Introduction

Geologists travel. Our movements generally follow earth phenomena rather than social or political motives, but many of us cannot help but be affected by the inequalities of the conditions of man across the earth. Drastic inequalities in resources (clean water, food, basic materials, education, and health services) are often linked to the availability of the affordable energy necessary to drive the complex industrial structure that is required for an adequate way of life. Given the present global population of 4.5 billion, and the reasonable certainty that this will double in the next century, we must (unless we are to live in worlds of C.P. Snow's "nuisance" or Aldous Huxley's "catastrophe") greatly expand - by tenfold perhaps - the energy currently available to us.

In the early part of this century, following the revolution in our knowledge of physical science, atomic energy offered a great future source of energy. Today, more than 200 fission reactors produce over $6 \%$ of the global electricity needs and, if future projections of many nations are correct, this figure will increase dramatically. Even in a country as environmentally conscious as Sweden, the nuclear power capacity will double in ten years. And the non-politically motivated Club of Rome (Gabor et al., 1978) has recently concluded that "... a further development of nuclear fission energy today represents an unavoidable choice for the industralized countries". The same may well be true for many overpopulated and less fortunate nations where malnutrition and infant mortality are rampant.

Until light-electricity conversion becomes an economic reality, it is difficult to see any viable alternative to nuclear energy. Biomass systems (such as gasohol, for example) compete with food production, while any vast increase in global coal usage, with its effects on metal pollution, $\mathrm{CO}_{2}$ build-up, and acid rain, could lead to a global environmental catastrophe beyond our means to control.

\section{The Problem and Objectives}

Three main problem areas are associated with the present uranium fuel cycle: (a) pollution from large scale mining (uranium, thorium, radium); (b) pollution from power, fabrication, and chemical plants associated with the fuel technology; (c) pollution from radioactive waste products of the fuel cycle. This article focusses on (c) rather than (a) or (b) or issues related to human catastrophies which appear in armed conflict, sabotage, and the like.

A major objective must be to minimize changes in our environment. Most earth scientists are all too aware of the sensitivity of biological populations to environmental change. We also know that testing the effects of any perturbation on a long-lived species must require times that are longer in orders of magnitude than the life span of the species. Thus, our target must be to limit the range of man-made perturbations to the range of natural perturbations which macroorganisms have managed to tolerate over long periods of time (such as variation in the natural radioactivity of the land surface, or the underground well water). And, as some of the FPISONFS. Vol. 1980. Nn. 3 nuclides synthesized in power reactors have half lives over $10^{6}$ years (iodine-129, $1.6 \times 10^{7}$; cesium-135, 2.3 x 106; neptunium-237, $2.1 \times 10^{6}$ ), the time constants of isolation must be long.

Fortunately, most of the radioactivity in spent fuel is in species with half lives measured in a few years, or less. For fuel discharged from the Canadian reactor CANDU, radioactivity drops from 2 million curies per bundle after use, to 1,600 after 10 years, and heat production drops in a corresponding way. It is probably realistic to propose that the major objectives of disposal must be to isolate the materials from the biosphere for periods exceeding a million years, and to be certain that leakage, when it occurs, will be slow and highly dispersed, so that no species is subjected to large pulses of radiation or concentrations of strange nuclear species. If the problem can be solved with a high degree of certainty, the influence on global energy policy will be profound.

Common questions asked by any thinking scientist or layman include "Have you any evidence it can be done?" "Surely, you cannot isolate materials in rocks for millions of years?" Certain features of rocks clearly show that this is possible: minute crystals of soluble sodium chloride can te isolated from water flow for billions of years; metals like copper can be preserved from oxidation and other forms of chemical corrosion for billions of years; minerals like periclase ( $\mathrm{MgO}$ ), highly sensitive to rapid hydration, can be preserved in impermeable rocks.

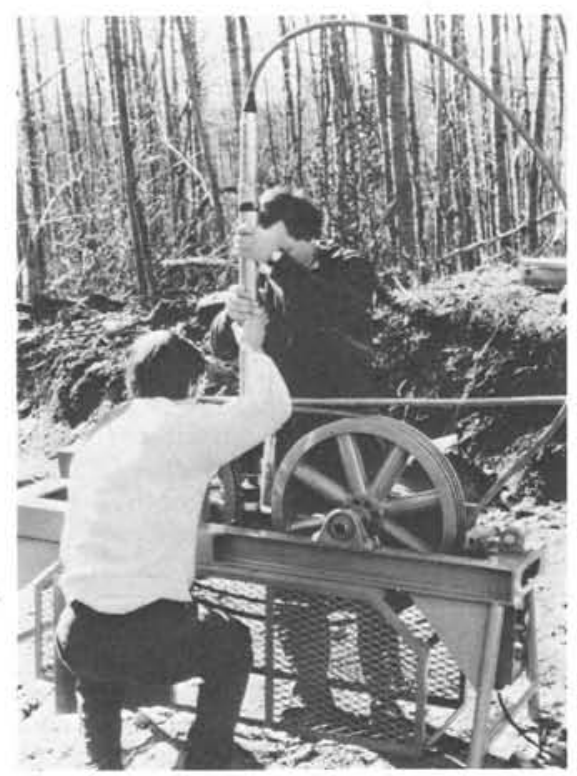

Lowering a television camera down a borehole to study fractures and other structures as part of a survey of repository sites, Chalk River, Canada. (Photo courtesy AECL) 


\section{The Major Geological Questions}

When we consider the disposal of any long-lived toxic species underground, the following questions are likely to arise: (a) Where is the best place? (b) What is the best rock type? (c) How deep do we put it? (d) How do we package the material? (e) How do we seal the cavities? (f) What will we do if it leaks? Earth scientists resolving such questions rapidly discover that there are serious gaps in our basic knowledge.

Where?

Ignoring disposal in space (rockets are expensive and not completely reliable), one then contemplates the ocean floor crust or the continental crust. In either case, one must choose a site that is tectonically stable. As the ocean floor crust is part of the mobile conveyer belt of plate tectonics, one is naturally attracted to the very stable floating continental rafts. Furthermore, should major leakage occur, one wonders how difficult it would be to seal, or even detect, a sea floor event. Also, continental mining technology is far more advanced and reliable than that for the sea floor.

To most earth scientists, a stable crustal region is one which yields very old ages. If various dating techniques, with differing memory stability (for example, $\mathrm{K}-\mathrm{Ar}$, Rb-Sr), yield the same age, then the case for a particular region is that much better.

Scientists involved in dating rocks generally choose the "bestlooking" rocks, avoiding anomalous zones, cracks, and the like. In the waste disposal context, stable implies that: (a) the permeability caused by pores and factures of an appropriate volume of rock is very low, or minimal; (b) new cracks, leading to enhanced permeability, are not likely to be produced during the next few million years; (c) the region will not be subjected to rapid erosion; (d) changes in hydrogeologic regimes will not occur, because of man-induced seismic events, glacial loading or unloading, or even meteoric events.

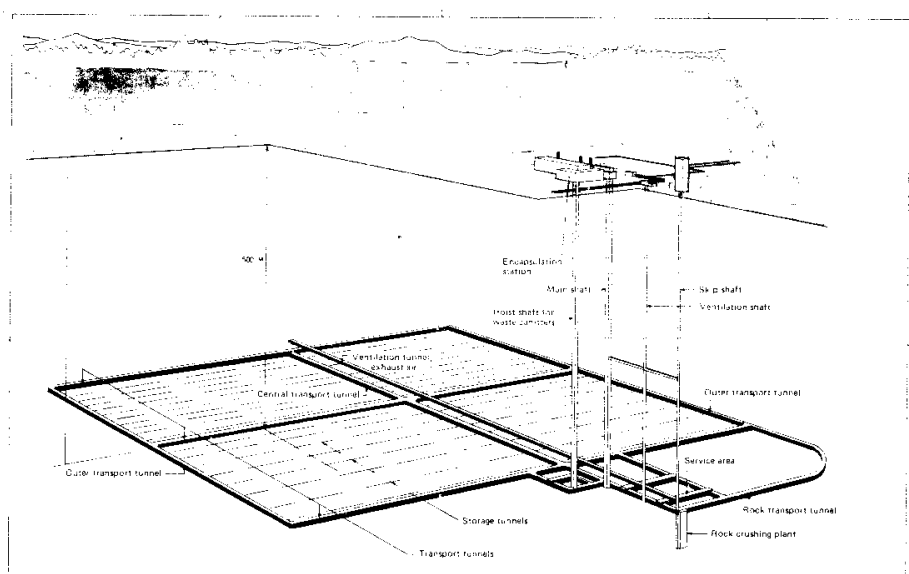

Swedish concept of a repository. It has been questioned if it is deep enough.

Thus, we are not so much concerned with conventional stability as with predictable long-term low permeability. A number of interesting questions arise. For example, most rocks have old and new fractures, some open, some healed. But can we date cracks? Another issue is the distribution of reactors which does not necessarily reflect the distribution of ideal crust; if one nation has reactors in a seismically unstable region (such as Japan perhaps), will that nation borrow crust in another region? The latter point underlines the urgent need for international regulation.

An intriguing question concerns the possible use of subduction zones. While current data are not adequate, recent seismic studies and very limited drilling in trenchwall environments (Jones et al., 1979) indicate that there may be some trench environments where sediments are not scraped off the des-

EPISODES, Vol. 1980, No. 3

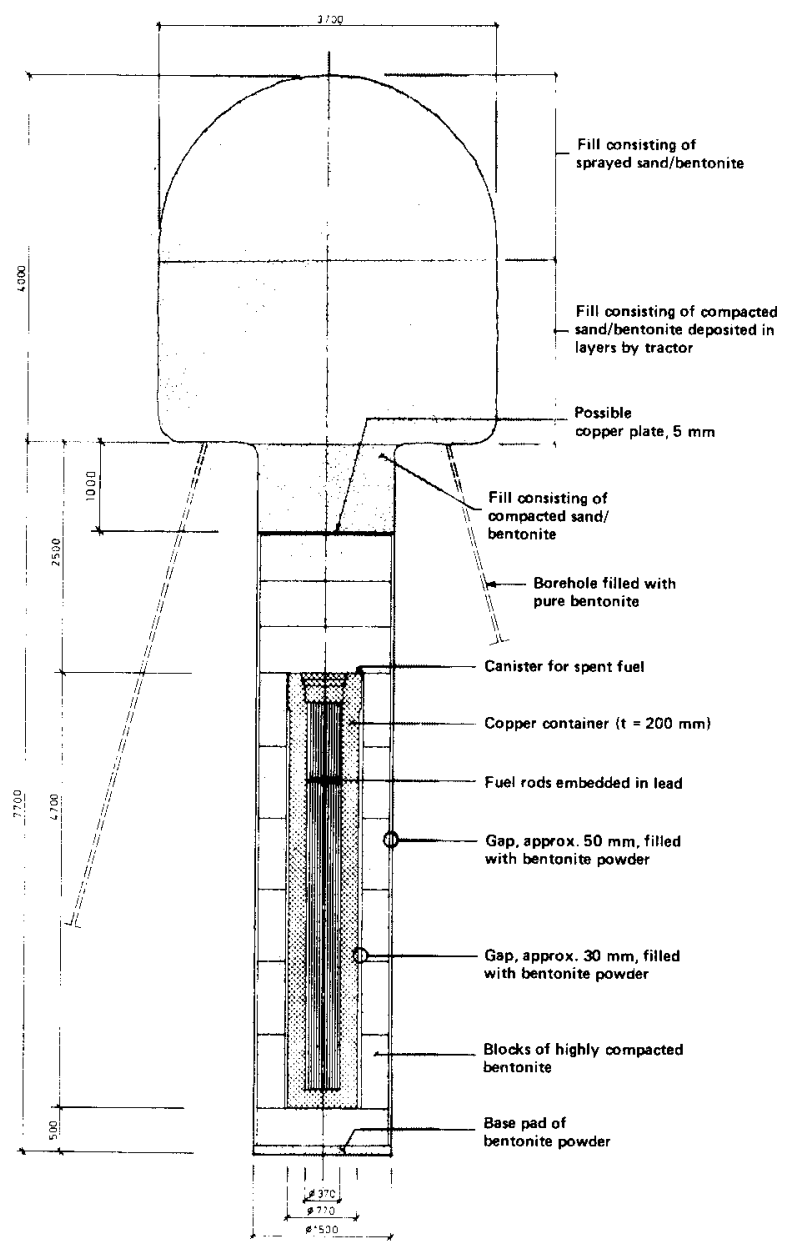

Swedish concept of repository configuration with spent fuel rods, buried in lead, surrounded by copper, and sealed in compressed bentonite (dimensions in $\mathrm{mm}$ ).

cending ocean floor crust, but may be carried to depth in the mantle, or perhaps rolled under lighter continental crust. Andesite chemistry, and its variability, further suggest that this phenomenon is important. Given that the subduction rate is $10 \mathrm{~cm}$ per year, a waste canister would thus arrive at a depth of $1 \mathrm{~km}$ in ten thousand years and, after a million years, would be safely buried at $50 \mathrm{~km}$ or so, depending on the subduction angle. The possibility of using an ultra-deep natural burial process might be considered more feasible than disposal in outer space.

What is the ideal depth?

Discussions in the Canadian and Swedish literature on disposal generally centre around possible depths of 500-1,000 m. Some groups in the U.S.A. consider it feasible to use very deep drilled holes with depths of 5 to even $15 \mathrm{~km}$. In general, it is well known that porosity tends to decrease with depth and that cracks seal by pressure solution. But most of our most precise knowledge comes from the water/oil/gas industries searching for rocks where fluid flow is essential. There are very few detailed studies on deep flow regimes in what might be ideal rocks for a repository.

Advantages of depth include faster closure of cracks, faster pressure-solution phenomena, lower porosity, longer flow paths, and greater flow dispersion (dilution). The disadvantages are generally associated with technical problems and cost, higher local temperatures, and greater solubility of toxic species.

A much greater effort in experimental deep drilling is needed as well as a greater use of data from very deep $(2-4 \mathrm{~km})$ large mining operations. Dr. Neville Price of Imperial College, U.K., recently presented data which suggests that there is a significant risk from meteorite impacts, concluding that, to reduce such risk, burial should be as deep as is technically feasible - that is, at least $2 \mathrm{~km}$. 
The ideal rock?

From present plans, a repository will have a volume involving something like a $10 \mathrm{~km}^{3}$ block (many simple plutons have a volume of about $500 \mathrm{~km}^{3}$ ). Most agree that the repository rock should be as isotropic, both mineralogically and structurally, as possible. This condition might be relaxed for a very deep drill concept, where a pluton overlain by shales, for example, might be ideal.

Given the appropriate volume, a large number of additional features must be evaluated: (a) the rock must be of low porosity and free of fractures, particularly young, unhealed fractures; (b) the rock should be free of fluids, and particularly of salty fluids which can enhance metal transport; (c) the rock should be of low radioactivity, and in a region of minimal heat flow; (d) the minerals of the rock should be good for ion-exchange or adsorption processes; this generally implies an array of minerals with structural sites of different size and coordination numbers, both for cations and anions; (e) the rock should be resistant to the thermal stress that will occur near the waste; (f) the rock should be plastic, and rapidly heal any fresh cracks; $(\mathrm{g})$ if new fractures form, the rock should have the best re-sealing properties: this will of ten imply that the rock contains anhydrous minerals, which swell when they hydrate; (h) the rock should be of little potential use to man as a mineral resource.

Considered all together, these factors make it clear that there is no ideal rock. For example, some granitic rocks might be good with regard to factors (a) and (h), but they are bad with respect to (d) and (f). Gabbro-peridotites might be excellent with respect to $(\mathrm{g})$, but not so good with (d) or (h). Shales are excellent with respect to (d) and (f), but not so good with (b) or (e). On many grounds except (f), salt might get a bad rating. A more positive solution might be to use a two layer system, such as granite under shale.

\section{Thermal effects and interim storage}

The waste from a reactor has a significant heat output which decays along with the radioactivity. Considerable research has been done on the perturbations likely to arise from the temperature rise near the repository. The great danger is that the temperature increase will promote hydraulic fracturing by dehydration processes, or by increases in pore pressure, and that this will be followed by fluid convection to the surface. Significant in situ experiments have been underway in Sweden for some time, and others are planned.

The problem becomes less severe if the waste is stored at the surface for long periods. Thus, a CANDU fuel bundle produces 2,000 watts a day after it leaves the reactor, 60 watts after one year, and about 1 watt after one hundred years. There appears to be an advantage in safe interior storage for a long period of time, as the size of a repository can be made smaller with the reduced thermal input, which is of particular importance in the deep drilled hole concept.

\section{Packing Technology}

Faced with geologic uncertainties such as difficulties in predicting the permeability of $10 \mathrm{~km}^{3}$ of rock, or whether a major new fracture a few $\mathrm{mm}$ in aperture will or will not appear, researchers have concentrated on the waste form, containers, and the best methods of sealing the entire system. As the latter are improved, the geologic uncertainties become less significant and burial is needed simply to "keep the stuff out of harm's way". (Many thoughtful scientists say it should be kept where we can see it and monitor it).

Without getting into the differences between unreprocessed and reprocessed nuclear wastes, and assuming that we have a solid waste, most of it will be in the form of metals, or metal oxides with small quantities of more volatile gases and species like iodides. Most simply, this waste could be packed into strong, corrosion-resistant containers. Proposals such as dissolving and diluting the waste in a stable glass are more complicated. Experimental petrologists and volcanologists have pointed out that glass tends to rapidly recrystallize when in contact with hot water.

EPISODES, Vol. 1980, No. 3

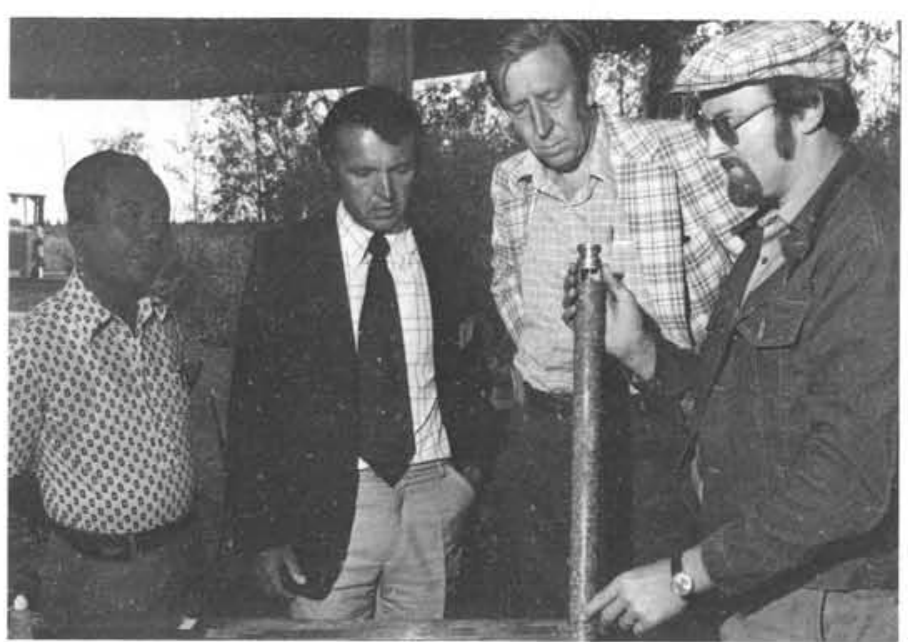

Visitors from OECD/NEA and the WNRE observe J. Dugal (far right) of the GSC orient a core sample from the Lac du Bonnet Batholith where possible repository sites are being evaluated. (Photo courtesy AECL)

Numerous workers (in particular, E.A. Ringwood of Australia) have suggested dispersing the radio nuclides in appropriate sites in very stable mineral structures - the SYNROC concept. The materials are prepared by high pressure, high temperature crystallization techniques. As long as the toxic elements are well dispersed in the host crystals and given the great insolubility of the minerals, this method has obvious advantages over glassy waste forms. Problems still remain with volatile species in the waste and with radiation damage to the crystal structures, but we can expect improvements in all of these proposals from the investigations underway in many countries.

A significant part of the Swedish research effort has been devoted to the concept of making containers last a long time. Obviously, if you can seal the waste in any solid form, in a container with walls that will not allow access of water for periods of a few million years, then all other related problems are greatly reduced. Possible approaches include using thick-walled $(20 \mathrm{~cm})$ copper vessels into which the waste is placed and buried in lead. Geological evidence clearly shows that the corrosion of native copper is related to the access of oxygen or sulphur-bearing fluids, as well as the mass of fluid available to react with the container. At depth, rocks buffer the oxygen at essentially zero levels, and sulphur at very low levels. Given reasonable values of these factors, the predicted lifetime of the container is in the million year range. Geological evidence shows that this is a very conservative figure.

Another fascinating approach being developed by ASEA of Sweden is the fabrication of large containers of high pressure, high temperature, sintered corundum. Again, all geo-

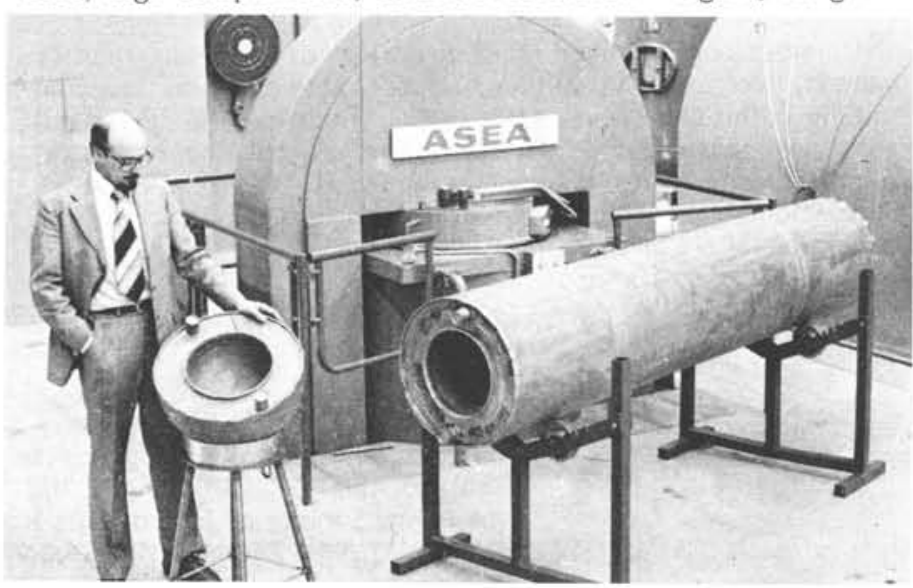

A high-pressure sintered corundum container manufactured by ASEA of Sweden. 
chemical evidence and observations from tropical weathering show that corundum is very insoluble and corrosion resistant. It is corroded by hydration reactions, forming minerals such as gibbsite or boehmite or even kaolin. The numerous studies of these corrosion rates indicate low temperature lifetimes of at least ten million years.

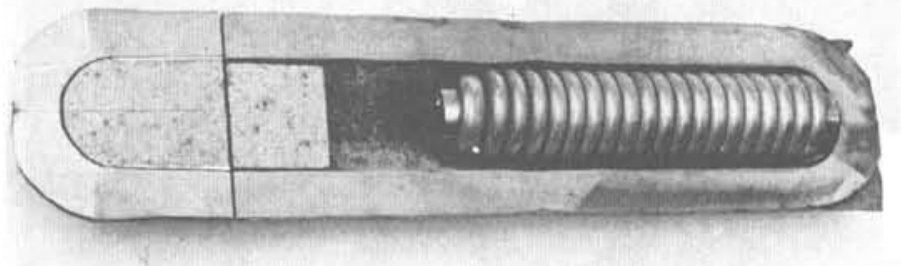

A one-third size corundum container loaded with a dummy compressed fuel rod. Sealing is achieved by high $P-T$ welding of the corundum.

Back-fill

Once containers are placed in a mined cavity or drill hole, the perturbed system must be sealed to maximum impermeability. The backfill must be designed for minimum permeability, and the material used should have good adsorption properties for any toxic species which may leak out. Again, there has been great progress in the development of such materials; proposals involve the use of compacted bentonite (swelling) clays, or quartz-bentonite mixtures. Laboratories at the University of Western Ontario, Canada, have used the large volume expansion produced when magnesium oxide hydrates to form brucite, to produce magnesium oxide-silica compacts with about the lowest permeability of any manmade cement, that is, in the range of the least permeable shales.

To the back fill can be added a host of minor minerals designed to specifically fix problem elements. Thus, native copper will fix iodine, due to the insoluble nature of copper iodide (as seen by iodine enrichment around copper ore bodies). Phosphate minerals are excellent scavengers for a wide range of metals, including radium and uranium - a phenomenon observed in natural-occurring phosphates.

Should the container and back fill be breached, toxic species may be absorbed and diluted on the long flow path through the host rock, the final barrier.

\section{Conclusion}

Several sound approaches to waste disposal are available now. With the large research effort underway around the world, they will be improved and new and more economic technologies will be developed. New mining methods may minimize rock disturbance. On this count, it would seem undesirable to build very large repositories in the first instance.

With solutions at hand for disposing of nuclear reactor wastes, we must now focus closer attention on uranium mining pollution. Here too there is evidence that practical solutions will resolve the problem in the near future. Furthermore, continued research in all these areas will revolutionize our knowledge of fracturing and fluid flow in the outer layers of the earth's crust.

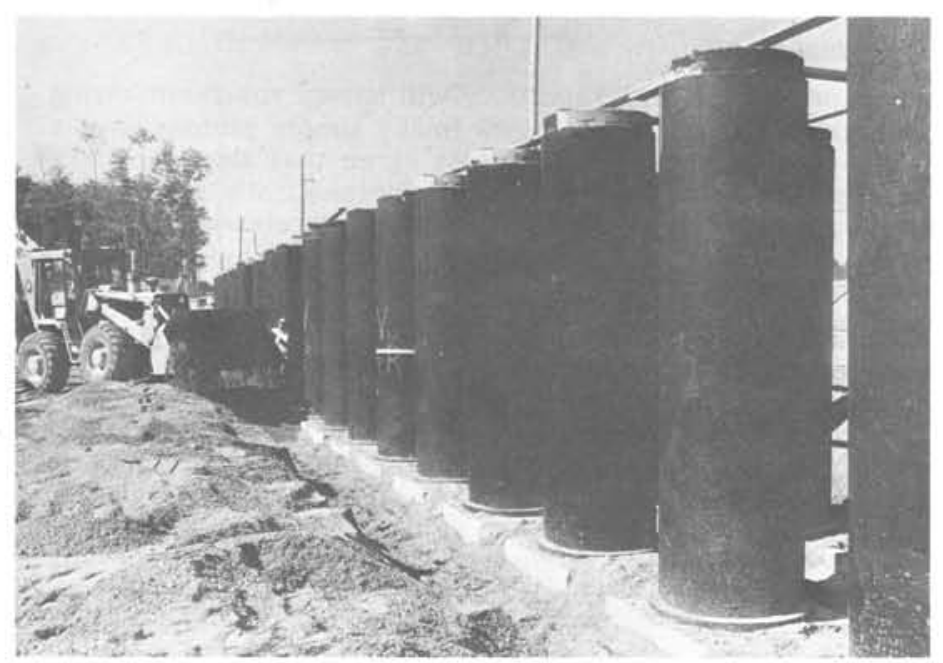

Low-level waste from nuclear power operations is placed in concrete containers within backfilled trenches - scene above is at the Bruce Generating Station " $A$ ", Canada. (Photo courtesy Ontario Hydro)

\section{References}

Boulton, J., (ed.), 1978, Management of radioactive fuel wastes: the Canadian disposal program: Atomic Energy of Canada Research Co., 135 pp.

Gabor, D., Colombo, U., King, A. and Galli, R., 1978, Beyond the age of waste (a report to the Club of Rome): Pergamon, 237 pp.

Jones, G.M., Hilde, T.W.C., Sharman, G.F. and Agnew, D.C., 1979, Fault patterns in outer trend walls and their tectonic significance, in S. Uyeda, R.W. Murphy and K. Kobayashi (eds.), Geodynamics of the Western Pacific: Japan Scientific Societies Press, Tokyo, pp. 68-74.

Kärn-Bränsle-Säkerhet, (Nuclear - Fuel - Safety), Sweden, 1978, Handling and final storage of unreprocessed spent nuclear fuel: $325 \mathrm{pp}$.

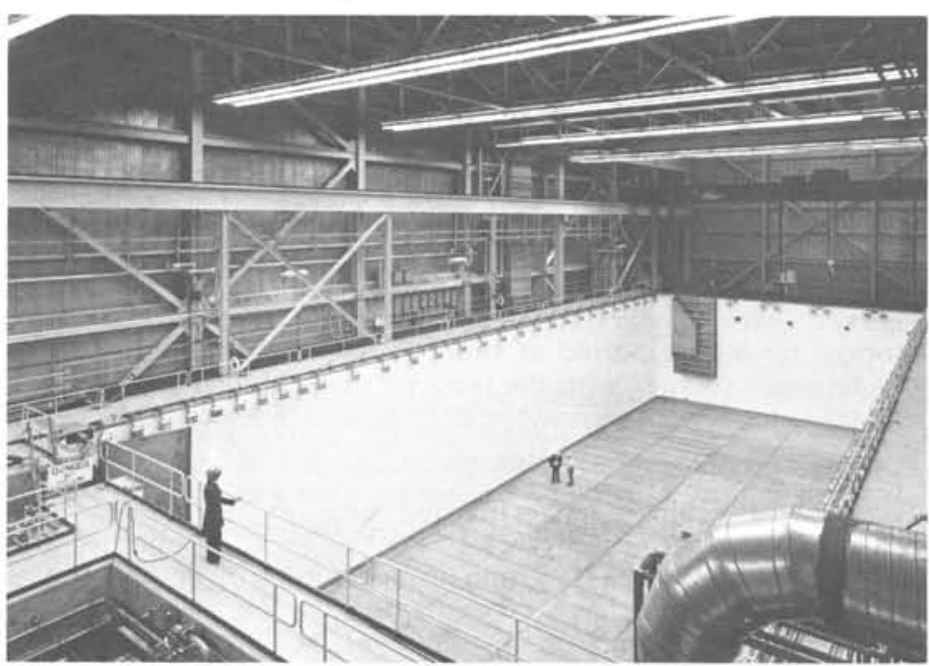

Ontario Hydro's Bruce Generating Station, Canada: spent fuel is stored underwater in large bays on the nuclear power station premises. (Photo courtesy AECL)

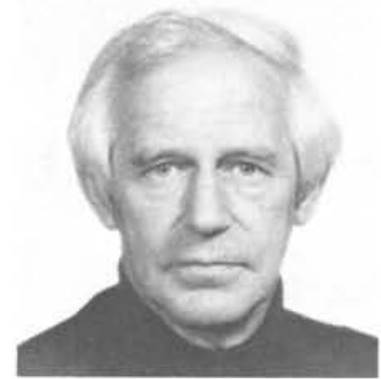

EPISODES, Vol. 1980, No. 3
ABOUT THE AUTHOR: Born and educated in New Zealand, William S. Fyfe is now Chairman of the Department of Geology, University of Western Ontario, Canada. He has lectured in the U.S.A., New Zealand, the U.K. and Canada, has authored five textbooks and over 150 research papers. A fellow of the Royal Society of London, the Royal Society of Canada, he is also an honorary fellow of the Royal Society of New Zealand, the Geological Socie y of America, and an honorary member of the Academy of Science in Brazil. Dr. Fyfe is Chairman of the ICSU Sub-Committee on the Terrestrial Disposal of Nuclear Waste, one of the three working groups under the Steering Committee on Radioactive Waste Disposal. 